\title{
Compositional analysis of interrogative imperatives in Hungarian
}

\author{
Judit Kleiber and Gábor Alberti \\ University of Pécs, Hungary
}

\begin{abstract}
The paper investigates utterances which combine imperative and interrogative elements in Hungarian. We intend to explore the scope of the hypothesis that the pragmatico-semantic content of mixed-type sentences can be obtained compositionally. We present four types of interrogative imperative. The imperative factor is indicated by subjunctive morphology on the verb. The interrogative character is represented by (1) rise-fall intonation which marks polar questions, (2) the discourse marker ugye expressing bias, (3) the particle vajon expressing selfreflection or hesitation, and (4) wavy intonation which indicates surprise. We claim that such sentences are primarily questions with their main function being 'request for instruction'. For the analysis, we take a formal pragmatico-semantic point of view. Our goal is to demonstrate how these sentences can be analyzed compositionally within a belief-desire-intention frame. We apply the formal dynamic discourse- and mindrepresentation theory $\Re$ ReALIS. We have found that the pragmatico-semantic content (intensional profile) of each type can be constructed via using two formal operations: concatenation and pragmasemantic blending. The composition produces the required output, namely that the interrogation / bias / speculation / surprise which pertains to an eventuality in the case of a simple question, pertains to the "commanding" of this eventuality in the case of interrogative imperatives.
\end{abstract}

Keywords: pragmatico-semantic analysis, belief-desire-intention framework, discourse representation theory, discourse markers

This paper investigates utterances which combine imperative and interrogative elements in Hungarian. We intend to explore the scope of the obvious null hypothesis that the pragmaticosemantic content of mixed-type sentences can be obtained compositionally in a well defined sense which requires innovative ideas in pragmatics.

Interrogative imperatives are typically used for requesting instruction as to whether the addresser should do something or not. This function is best carried out by the basic type of interrogative imperative, which has rise-fall intonation used for marking a polar question, along with subjunctive morphology on the verb indicating imperative content. We demonstrate that the meaning of this sentence type can be constructed compositionally as the combination of the meanings of the basic polar question and the basic imperative sentence type. Furthermore, we 
present three additional types of interrogative imperative which carry out slightly different functions. We examine the addition of the discourse marker ugye expressing bias, the particle vajon expressing self-reflection, and a non-standard, wavy intonation pattern indicating surprise.

For the analysis, we apply the formal dynamic discourse- and mind-representation theory ReALIS, in which - along with the external world - the interlocutors' internal worlds (mind states) are also represented. We use two formal operations, concatenation and blending between the intensional profiles of the components which encode the interlocutors' beliefs, desires and intentions when uttering these sentences. As a result, we will reach a position to be able to construct the pragmatico-semantic contents of the four types of interrogative imperative. The analysis accounts for the intuition that these sentences can be regarded as questions which are targeted at the commands in them. With simple polar questions, the addresser wants to know if an eventuality is true or false, whilst with interrogative imperatives, the question pertains to the "commanding" of an eventuality: the addresser inquires whether the addressee wishes/intends the addresser to carry out a particular action.

The paper is organized as follows. First, we present the data: four types of interrogative imperative in Hungarian, their relevant formal features, and their prototypical functions. Then we briefly introduce ReALIS, the framework applied, concentrating on the relevant features and the formalism. This is followed by the formal analysis of interrogative imperatives. We present the pragmatico-semantic content of the components from which these sentences are built up, and then the process and the outcome of the composition.

\section{Interrogative Imperatives in Hungarian}

\section{Literature Review}

There are very few literature on interrogative imperatives in Hungarian. Turi (2009) mentions them briefly while arguing that Hungarian grammar includes a subjunctive mood. He claims that these instruction-seeking questions (as he calls them) can or cannot contain an imperative operator, which is responsible for the two possible word order variants. Varga (2013) discusses the subject in slightly more detail in her thesis about the syntax of Hungarian imperative sentences. She claims that they contain both interrogative and imperative operators with the former having scope over the latter. Both papers mention only the basic type, and their interest is mainly syntactic. In this paper, we examine these sentences more thoroughly, and primarily from a pragmatico-semantic point of view focusing on their meaning and usage.

\section{The Data}

Interrogative imperatives are mixed-type sentences which combine interrogative and imperative elements. The verbs all contain the suffix $-j$ traditionally called imperative mood marker in Hungarian. We follow Turi (2009) and Varga (2013) in assuming that only subjunctive mood exists at the level of morphology; and imperative is encoded at the level of 
syntax. This claim is supported by the fact that imperatives have a full paradigm in Hungarian, meaning that the verb can be conjugated in every person and number, contrary to many languages, like English for instance, which use auxiliary verbs (e.g. should) for non-secondperson imperative verb forms (we will give a few examples later on). In interrogative imperatives, subjunctive morphology occurs with question-like elements: characteristic intonation patterns and/or discourse markers. In this paper, we examine the presence of the basic rise-fall intonation which marks polar questions, the discourse particle ugye which expresses bias (leading questions), the discourse particle vajon which expresses self-reflection ('I wonder...'), and a non-standard, wavy intonation pattern which indicates surprise.

As their main function, they all express a request for instruction - at a certain level (to be elaborated on). They are basically questions targeted at the commands in them inquiring whether one should do something or not. Let us discuss the four types one by one, starting with the basic type where the subjunctive verb form appears in a plain polar question characterized by rise-fall intonation and no discourse markers. This is followed by the presentation of three additional types where the interrogative component is somewhat marked: they are indicated by discourse markers or a non-standard intonation.

\section{The Basic Type: Subjunctive Morphology with Rise-Fall Intonation}

The first type of interrogative imperative we discuss has a subjunctive verb form; it is marked by a rise-fall intonation pattern (where the rising pitch is on the second-to-last syllable); and it does not contain discourse markers. It is the combination of the basic polar question and the basic imperative sentence type (1).

(1) Subjunctive + rise-fall intonation (typically used with polar questions) call.Sbjv.1Pl call.Sbjv.2Sg help.Acc 'Should we / ?? you call for help?'
a. Hívjunk / ??Hívjál segítséget?
b. Fel-hívjam / (?)Hívjam fel Marit? vm-call.Sbjv.1Sg call.Sbjv.1Sg vm Mari.Acc (vm: verbal modifier) 'Should I call Mari?'

The preferred verb form for this type is the first person singular or plural, while there is a strong dispreference against the second person forms, especially in singular (1a). This is a reversed preference compared to interrogatives and imperatives: with questions and commands, the second person is preferred, and the first person is dispreferred, at least with the basic types (more on this matter in the analysis section). The verbal modifier can both precede and follow the finite verb (1b); though the nuclear word order (verbal modifier-verb) sounds a slightly more neutral.

As for its function, it is the default type used for requesting instructions. It means something like 'I want to know your desires/intentions regarding eventuality e'. The expected answer is igen 'yes' or ne 'no' in Hungarian, which is an argument for the claim that these 
utterances are primarily questions. The imperative content is indicated by the use of the $n e$ form of the negation word instead of the declarative nem 'no'.

This basic type has been briefly discussed in the Hungarian literature. Varga (2013) uses the term interrogative imperatives, while Turi (2009) refers to them as instruction-seeking questions. They both agree that these sentences can be categorized as interrogatives which also have a directive component. They claim that - at the level of syntax - the two different word orders distinguish (real) imperatives from subjunctive clauses with an imperative meaning: specifically, nuclear word order characterizes the latter, while inverted word order (verb-verbal modifier) defines the former. Varga (2013) argues that, in the case of main clause imperatives - regarded as matrix subjunctive clauses - the unusual nuclear word order can only be licenced by a sort of givenness in the discourse. In the case of interrogative imperatives, however, as pointed out by her, both word orders are acceptable without such semantic/pragmatic constraint (p. 87).

\section{Three Additional Types of Interrogative Imperative}

The second type to be discussed has a subjunctive verb form, and it contains the discourse marker ugye which expresses bias (similarly to tag questions in English). This type can be regarded as the combination of the biased polar question (ugye-interrogative) and the basic imperative (2). It is typically marked by a rise-fall intonation pattern where the position of the rise is usually on the most prominent constituent (the object in (2a), and the verb in (2b)). For more information on ugye and intonation, see Gyuris (2009), for instance.

Subjunctive + ugye (expressing bias)

a. Ugye fözzek / ??fözzél $\quad$ levest is?
ugye cook.Sbjv.1Sg cook.Sbjv.2Sg soup.Acc also
'I / ??You should also make a soup, shouldn't I / 'you?'
b. Ugye meg-fözzem / (?) fözzem $\quad$ meg a levest?
ugye vm-cook.Sbjv.1Sg cook.Sbjv.1Sg vm the $\quad$ soup.Acc
'I should prepare the soup, shouldn't I?'

Verb form preferences are the same as with the basic type: the first person is preferred, while the second person is strongly dispreferred (2a). Both word orders are acceptable with the nuclear one being the more neutral (2b). The main function (requesting instruction) is somewhat modified: the expected answer is confirmation, this is why the negative answer needs some explanation - although, not as much as a simple ugye-interrogative does.

The next type we discuss has subjunctive verb form, and it contains the discourse marker vajon 'whether', which expresses self-reflection (Gärtner \& Gyuris, 2012), similarly to the English clause 'I wonder'. Its intonation is analogous to that of a simple polar question: risingfalling with the rise on the penultimate syllable. Thus, this type combines vajon-interrogatives and the basic imperative (3). 
(3) Subjunctive + vajon (expressing self-reflection)

a. Vajon menjünk / 'menjél ma futni? vajon go.Sbjv.2Pl go.Sbjv.2Sg today run.Inf 'I wonder whether we / 'you should go running today.'

b. Vajon el-menjek / 'menjek el a koncertre? vajon vm-go.Sbjv.1Sg go.Sbjv.1Sg vm the concert.Sub 'I wonder whether I should go to the concert.'

This type also prefers first person verb forms, especially in the plural. Second person is dispreferred, but not as much as with the previous types (3a). Another difference from the previous types is that, with vajon, the inverted word order is much less acceptable than the nuclear one (3b). As for its function, the speaker is requesting the listener's opinion in this utterance. It means something like 'I do not think you know the answer, I just need your advice.' The reply usually begins with 'I think' or 'Maybe' indicating that the interlocutors are starting to speculate together over the action in question.

The last type to be discussed here has subjunctive morphology accompanied by a wavy intonation, which expresses surprise (Kleiber \& Alberti, 2014). With this special intonation, an interrogative sentence can be regarded as an exclamation rather than a question (Varga, 1994). So this type is a combination of exclamative polar questions (wavy interrogatives) and basic imperatives (4).

(4) Subjunctive + wavy intonation (indicating surprise)

a. (Tényleg) Olvassak / 'Olvassál Marinak esti mesét?! really read.Sbjv.1Sg read.Sbjv.2Sg Mari.Dat bedtime_story.Acc

'I / 'you should (really) read a bedtime story to Mari?!'

b. (Tényleg) 'El-olvassam / Olvassam el az egész könyvet?! really vm-read.Sbjv.1Sgread.Sbjv.1Sg vm the whole book.Acc

'I should (really) read the whole book?!'

First person verb forms are preferred, while the second person is dispreferred; though similarly to the previous type containing vajon - the dispreference against second-person verb forms is not that strong (4a). Contrary to all the other types, the inverted word order is much more common than the nuclear one (4b), which can be explained by the fact that this type is primarily used as a counter-question known to repeat the original structure (Varga, 2013, p. 87): an imperative sentence following inverted word order in this case. The function of this type is to express surprise over an instruction. With this utterance, the speaker is typically expecting confirmation, explanation, or merely the listener's sympathy.

\section{Framework: ReALIS}

ReALIS 'Reciprocal And Lifelong Interpretation System' (Alberti, 2011) can be characterized as a discourse-representation-based (Kamp, Genabith, \& Reyle, 2011; Asher \& Lascarides, 2003) formal pragmasemantic theory. Reciprocal means that the interlocutors model each other 
reciprocally: the speaker, for instance, when utters a sentence, takes the listener's assumed knowledge into consideration, including their assumed knowledge exactly on the speaker's knowledge. Lifelong means that a huge DRS (discourse representation structure) is built from birth, containing the interpreter's information states from moment to moment. In order to account for pragmatic phenomena, we need to represent not only the outside world but also the interlocutors' internal worlds (mental states): their beliefs (B), desires (D) and intentions (I).

The innovative feature of $\Re$ eALIS is that representations are regarded as mental states (the interpreters represent discourses in their minds), and these mind-representations are taken to be part of the world model (Alberti \& Kleiber, 2014). In this way, a homogeneous structure is used for representing the discourse, the world, and the human mind. With this approach, the same pattern-matching mechanism can be applied for extensional and intensional evaluation, which makes it possible to check the sincerity of a promise, for instance, the same way as the truth value of a sentence.

In ReALIS, it is possible to differentiate between the addresser/addressee and the speaker/listener roles. The former belongs to the ideal case, the linguistically encoded information of an utterance (this is our only concern in the paper), while the latter appears in a concrete situation which may not realize the ideal case. During the interpretation process, it is to be evaluated from clause to clause - in harmony with Oishi's (2014) thesis - whether the speaker is acting legitimately, sincerely, and/or adequately, while, in the on-going discourse, playing the addresser's role and giving the listener the addressee's role and qualifying the speech situation to be a licensed context of the given speech act. With this approach, when a proposition is evaluated against the current content of the interlocutors' information state, various pragmatic factors can be accounted for, such as the Gricean maxims (e.g., the relevance of an utterance), irony, politeness, and so on (for more on this matter, see Alberti, Vadász, \& Kleiber (2013); and Alberti, Kleiber, Schnell, \& Szabó (2016)).

In the remaining of the section, we briefly introduce the applied formalism, that is, how representations look like in ReALIS. A clause performed in an on-going discourse conveys a piece of information which belongs to an intensional profile encoding its pragmatico-semantic contribution: the interlocutors' beliefs, desires and intentions while performing it. An intensional profile consists of finite components of worldlets which encode one meaning component each, such as a desire for an eventuality, or a belief about the intentions of our partners. A worldlet can be regarded as a labeled DRS-like structure where eventuality e is "inside" the box, and the label encodes the five essential properties which belong to e in this particular case (5).

(5) The worldlet labels of $\Re$ eALIS
M: Modality
belief (B), desire (D), intention (I)
I: Intensity of $\mathrm{M}$
maximal (M), great (gr), some (sm), ..
$\mathrm{R}$ : host of the worldlet
addresser $(A R)$, addressee $(\mathrm{ae})$, others $(r, \ldots)$
T: time parameter
$\tau, \tau^{-}(<\tau), \tau^{+}(>\tau), \ldots$
P: polarity value
+ (true), - (false), 0 (neutral) 
For instance, if the sentence is I know that Peter loves Mary, then e='Peter loves Mary', and the label encodes its status: that the addresser ( $\mathrm{AR}=\mathrm{I})$ knows (Maximally Believes) at time $\tau$ that the given eventuality e holds $(+):\langle\mathrm{B}, \mathrm{M}, \mathrm{AR}, \tau,+\rangle$.

Every parameter can have multiple values, which allows underspecification in the representations. For instance, the intensity of the modality is often specified only as much as "non-maximal" (nM); or the polarity value may be "non-neutral" (+-). Even the host can be underspecified, like when AR utters the imperative sentence 'Sit down!' which can convey not only AR's but also ae's desire. Furthermore, a worldlet can be embedded in another worldlet which makes it possible to refer to information states (recursion). For instance, the series of level labels $\langle\mathrm{B}, \mathrm{M}, \mathrm{AR}, \tau,+\rangle\langle\mathrm{D}, \mathrm{M}, \mathrm{ae}, \tau,+\rangle$ when assigned to a worldlet encodes that $\mathrm{AR}$ is sure that ae longs for e. Finally, a key property of $\Re$ eALIS is that a piece of information frequently appears in several worldlets simultaneously. When an eventuality e is represented in the interlocutor's mind, it is "scattered" like a prism scatters images multiplying a single image - this is why we call this phenomenon a prism effect. For instance, one can desire and also intend to do e (placing e in two worldlet boxes appropriately) while it might also happen that one comes to a decision concerning an intention in spite of their opposite desires (placing e in the negative segment of the worldlet of desire). Thus, a set of finite sequences of level labels is assigned to an eventuality referent (we will see many examples later on).

As a summary, we conclude this section with the mathematical definition for intensional profiles. An intensional profile is an element of the set $\mathbf{P}\left((\mathbf{P}(\mathrm{M}) \times \mathbf{P}(\mathrm{I}) \times \mathbf{P}(\mathrm{R}) \times \mathbf{P}(\mathrm{T}) \times \mathbf{P}(\mathrm{P}))^{*}\right)$ : the power set of the set of finite sequences of level labels. The first power set symbol (bold $\mathbf{P}$ ) captures the prism effect, the internal ones are responsible for underspecification, and the Kleene-star at the end enables recursion.

\section{Formal Analysis: the Basic Type}

This section presents detailed analysis for the basic type of interrogative imperative, which is the compositional combination of the basic polar question and the basic imperative in Hungarian (1). First, we introduce the pragmatico-semantic content of the components. This is followed by the presentation of the methods $\Re$ eALIS applies for constructing compositions. Finally, we demonstrate how the intensional profile of the basic interrogative imperative can be created.

\section{Pragmatico-Semantic Content of the Components}

We begin with the presentation of the basic imperative profile. We follow Lauer (2013) in assuming that - though illocutionary force varies widely - sentence types can be associated with conventions of use. For instance, "an utterance of an imperative conventionally commits the speaker to a preference for the imperative to become fulfilled" (Lauer, 2013, p. 136). In ReALIS, the imperative convention is encoded in the intensional profile of the "basic" imperative, that is, the representation of AR's beliefs, desires and intentions behind this intuition. 
The pragmatico-semantic content of the basic imperative can be captured with four pieces of information (example in (6), visual representation in Figure 1): AR's (maximal) belief that eventuality e does not hold (6b); AR's (non-maximal) belief that ae has the same belief (6c); AR's (maximal) desire for e (6d); and - most importantly - AR's (maximal) intention to get ae to (intend to) do (or facilitate) e (6e). The preferred Agent (Ag) with the basic imperative is ae (second person verb form), while the dispreferred Agent is AR (first person) (6f); nevertheless, this description is also valid for non-addressee-oriented directives (third person forms). Obviously, with imperatives, we can express much more: adding discourse particles, or uttering them with special intonation patterns could shade or specify ("fine-tune") their meaning. For the present discussion, other types of imperative are not relevant; the interested reader is referred to Alberti et al. (2016); and Kleiber, Alberti, \& Szabó (2016).

(6) The intensional profile of the basic imperative sentence type in Hungarian

a. Menjhaza!

go.Sbjv.2Sg home

'Go home!'

b. $\langle\mathrm{B}, \mathrm{M}, \mathrm{AR}, \tau,-\rangle \quad$ "I (AR) am sure that (the result phase of) the given eventuality e does not hold (i.e., you are not home)"

c. $\langle\mathrm{B}, \mathrm{nM}, \mathrm{AR}, \tau,+\rangle\langle\mathrm{B}, \mathrm{M}, \mathrm{ae}, \tau,-\rangle$ "I think that you (ae) are also aware of this fact."

d. $\langle\mathrm{D}, \mathrm{M}, \mathrm{AR}, \tau,+\rangle \quad$ "I long for this eventuality (you being home)."

e. $\langle\mathrm{I}, \mathrm{M}, \mathrm{AR}, \tau,+\rangle\langle\mathrm{I}, \mathrm{M}, \mathrm{ae}, \tau+,+\rangle \quad$ "I want you to intend to go home, at a later time $\tau+$."

f. Note: Preferred Ag=ae; Dispreference: $A g \neq A R$

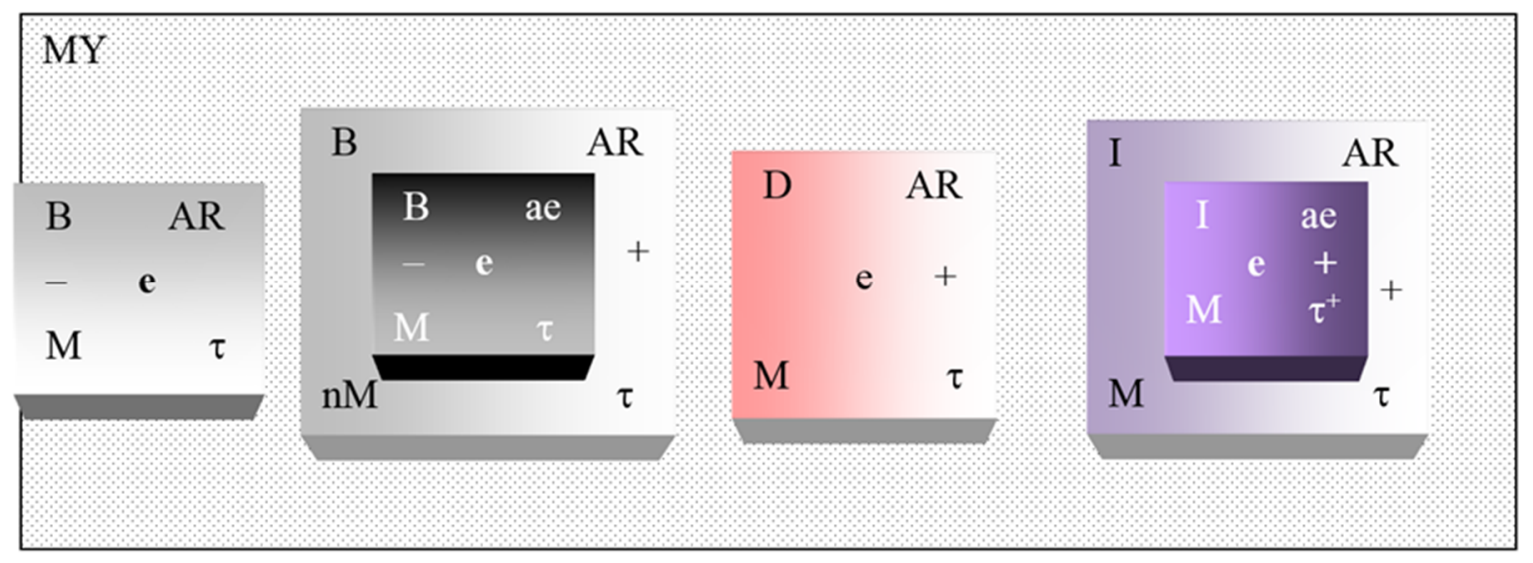

Figure 1: Visual representation for the basic imperative profile

The pragmatico-semantic content of interrogatives also exhibits great variation. In this part, we characterize the "basic" interrogative. Lauer (2013, pp. 162) defines the interrogative convention as follows: "The speaker requests that the addressee assert one of the possible answers to his question.”

In ReALIS, the intensional profile of the basic interrogative encodes four pieces of information regarding AR's beliefs, desires and intentions (7) (Figure 2). Compared to the basic imperative profile, AR's knowledge about eventuality e is neutral (0) this time (7b), while believing that ae's knowledge is not neutral (+ or -) (7c). Moreover, AR's desire (7d) and intention (7e) does not relate to e itself (to make e happen), but to know if e or not e holds. Verb 
form preferences are the same as with the basic imperative (7f). The relevant "fine-tuned" variants of the basic interrogative will be briefly discussed later in the paper; for more on this topic, see Alberti \& Kleiber (2014), and Kleiber \& Alberti (2014).

(7) The intensional profile of the basic interrogative sentence type in Hungarian

a. Péter otthon van?

Péter home be.3Sg

'Is Péter at home?'

b. $\langle\mathrm{B}, \mathrm{M}, \mathrm{AR}, \tau, 0\rangle \quad$ "I do not know if Péter is at home."

c. $\langle\mathrm{B}, \mathrm{nM}, \mathrm{AR}, \tau,+\rangle\langle\mathrm{B}, \mathrm{M}, \mathrm{ae}, \tau,+-\rangle \quad$ "I think you know the answer."

d. $\langle\mathrm{D}, \mathrm{M}, \mathrm{AR}, \tau,+\rangle\langle\mathrm{B}, \mathrm{M}, \mathrm{AR}, \tau+,+-\rangle \quad$ "I wish to know the truth."

e. $\langle\mathrm{I}, \mathrm{M}, \mathrm{AR}, \tau,+\rangle\langle\mathrm{I}, \mathrm{gr}, \mathrm{ae}, \tau+,+\rangle\langle\mathrm{B}, \mathrm{M}, \mathrm{AR}, \tau+,+-\rangle$ "I want you to intend to let me know

(at a later time $\tau^{+}$) if Péter is at home."

f. Note: Preferred Ag=ae; Dispreference: $A g \neq A R$

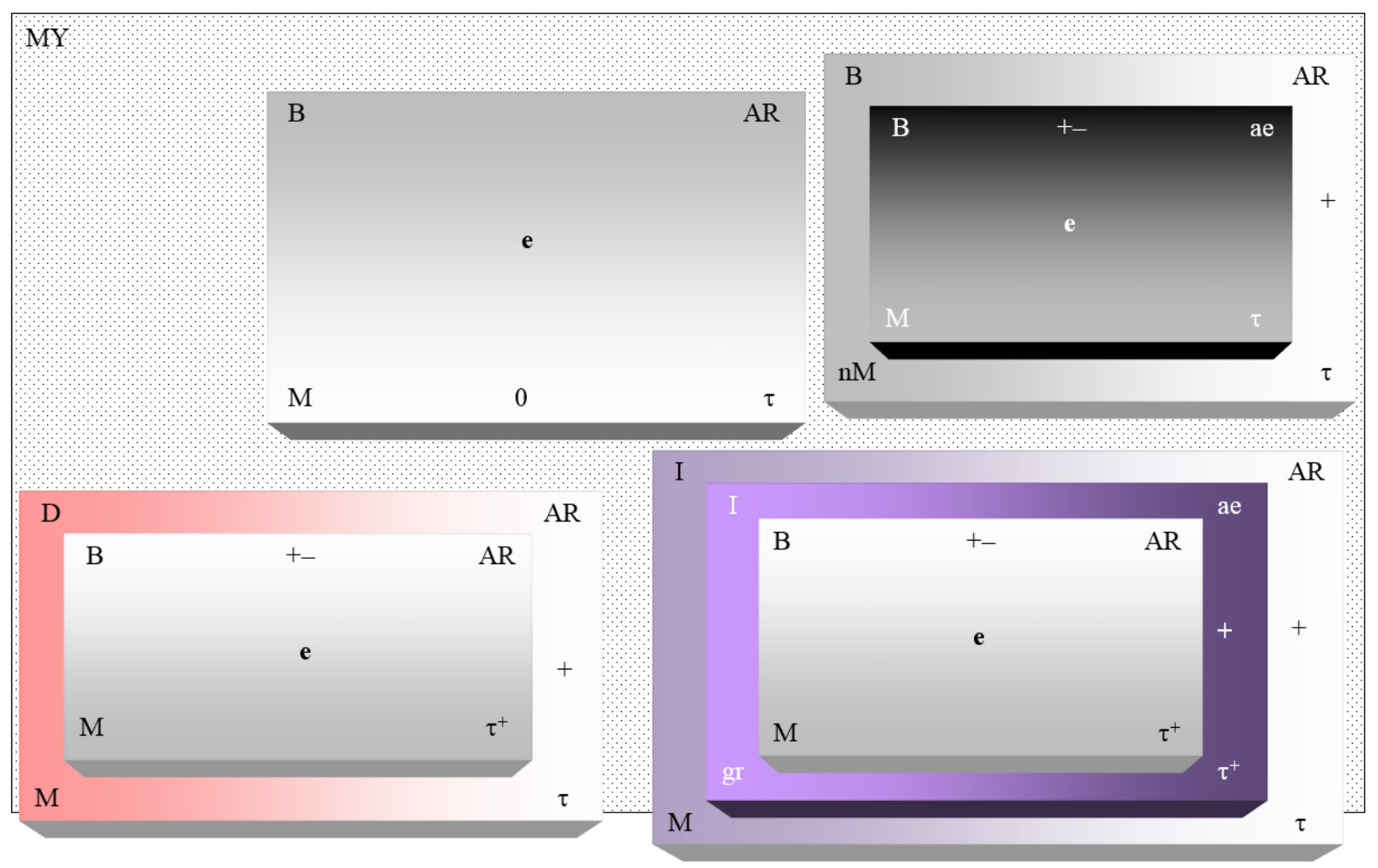

Figure 2: Visual representation for the basic interrogative profile

\section{The Composition}

ReALIS applies two means for providing compositional analysis (8): the simple (mathematical) operation of concatenation $(\wedge)$, and the formal operation of pragmasemantic blending $(\oplus)$. For the compositional analysis of interrogative imperatives, concatenation is applied to sets of worldlets, and it creates (deeper) embeddings. It allows two sets of worldlets to be mixed in a way that the labels of the first one will relate to the labels of the second one (instead of eventuality e itself): concatenation embeds the second worldlet into the first one. For instance, 
in (8a'), if we concatenate AR's desire for e with AR's knowledge about e, we get a worldlet where AR's desire is no longer for e itself, but to know e.

(8) Means for compositional analysis in ReALIS: concatenation (a) and blending (b)

a. $\quad\{A, B\}^{\wedge}\{C, D\}=\left\{A^{\wedge} C, A^{\wedge} D, B \wedge C, B^{\wedge} D\right\}=\{A C, A D, B C, B D\}$

a'. $\quad$ applied to worldlets: $\langle\mathrm{D}, \mathrm{M}, \mathrm{AR}, \tau,+\rangle \wedge\langle\mathrm{B}, \mathrm{M}, \mathrm{AR}, \tau,+\rangle=\langle\mathrm{D}, \mathrm{M}, \mathrm{AR}, \tau,+\rangle\langle\mathrm{B}, \mathrm{M}, \mathrm{AR}, \tau,+\rangle$

b. $\quad[X, Y, Z] \oplus\left[X^{\prime}, Y^{\prime}, Z^{\prime}\right]=\left[X \cup X^{\prime}, Y, Z^{\prime}\right]$

The operation of pragmasemantic blending is based on the cognitive linguistic notion, and it is capable of mixing partially incompatible meaning components, such as mood and modality (Alberti, Dóla, \& Kleiber, 2014). For deriving the pragmatico-semantic content of interrogative imperatives, we need to divide the intensional profiles into two sets of worldlets, and then mix them appropriately - which is exactly what blending can do. The premise components encode the beliefs about the eventuality in question, and about the interlocutors' internal worlds; while the central components represent the actual content of the utterance: desires, and, most importantly, intentions behind the speech act. The division is similar to the distinction between non-at-issue and at-issue content (Potts, 2005).

As we have already discussed, the basic type of interrogative imperative (1) is the combination of the basic polar question and the basic imperative sentence type. Its main function is to request instruction, asking what the Agent (preferably I/we) should do.

Now let us demonstrate how this type can be constructed (Table 1). The basis is the interrogative profile, since these sentences are primarily questions marked by a rise-fall intonation pattern. We have also established that these questions are targeted at the commands in them marked by a subjunctive verb form. Therefore, the imperative profile needs to be incorporated into the interrogative profile to provide the meaning we aim to derive. This task can be carried out by the concatenation between the two relevant intensional profiles; we only need to separate the premise components of the imperative profile first, and make them the premise components of the composition by using the operation of blending. 
Table 1: The construction of the pragmatico-semantic content of the basic type of interrogative imperative (BS: Basic interrogative + Subjunctive verb form)

\begin{tabular}{|c|c|}
\hline Composition: Basic type (BS) & $P \_\operatorname{Imp} \cup\left(\operatorname{Int}_{\text {basic }} \wedge\right.$ C_Imp $)$ \\
\hline \multirow{5}{*}{$\begin{array}{c}\{\langle\mathrm{B}, \mathrm{M}, \mathrm{AR}, \tau,-\rangle ; \\
\langle\mathrm{B}, \mathrm{nM}, \mathrm{AR}, \tau,+\rangle\langle\mathrm{B}, \mathrm{M}, \mathrm{ae}, \tau,-\rangle\} \\
\cup \\
\{\langle\mathrm{B}, \mathrm{M}, \mathrm{AR}, \tau, 0\rangle ; \\
\langle\mathrm{B}, \mathrm{nM}, \mathrm{AR}, \tau,+\rangle\langle\mathrm{B}, \mathrm{M}, \mathrm{ae}, \tau,+-\rangle ; \\
\langle\mathrm{D}, \mathrm{M}, \mathrm{AR}, \tau,+\rangle\left\langle\mathrm{B}, \mathrm{M}, \mathrm{AR}, \tau^{+},+-\right\rangle ; \\
\left.\langle\mathrm{I}, \mathrm{M}, \mathrm{AR}, \tau,+\rangle\langle\mathrm{Igr}, \mathrm{ae}, \tau,+\rangle\left\langle\mathrm{B}, \mathrm{M}, \mathrm{AR}, \tau^{+},+-\right\rangle\right\} \\
\wedge \\
\{\langle\mathrm{D}, \mathrm{M}, \mathbf{a e}, \tau,+\rangle ; \\
\left.\langle\mathrm{I}, \mathrm{M}, \mathbf{a e}, \tau,+\rangle\left\langle\mathrm{I}, \mathrm{M}, \mathrm{AR}, \tau^{+},+\right\rangle\right\}\end{array}$} & $\begin{array}{c}\text { Premise components } \\
\text { of the imperative profile (beliefs) } \\
\text { P_Imp }\end{array}$ \\
\hline & UNION \\
\hline & $\begin{array}{l}\text { Components } \\
\text { of the basic interrogative profile } \\
\text { Int }_{\text {basic }}\end{array}$ \\
\hline & CONCATENATION \\
\hline & $\begin{array}{c}\text { Central components } \\
\text { of the imperative profile (desire, intention) } \\
\text { C_Imp }\end{array}$ \\
\hline 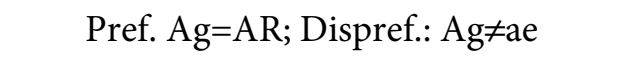 & reversed preferences (roles have turned) \\
\hline
\end{tabular}

The result of the above operation (Table 1) can be seen in the visual representation of the basic interrogative imperative (Figure 3). The basis is the interrogative profile (Figure 2), which has been altered in two ways. On the one hand, two extra boxes have been added via blending (premise components of the imperative profile). On the other hand, all the simple e's (eventualities) have been replaced with the same two boxes each (via concatenation): the central components of the imperative profile. Note that the roles have changed: if the imperative profile is embedded, AR becomes ae and vice versa, since now AR's command is the issue. In this way, we get the following interpretation (9) (AR=I, ae=you).

(9) The pragmatico-semantic content of the basic interrogative imperative sentence type
a. Hívjak segítséget?
call.Sbjv.1Sg help.Acc
'Should I call for help?'
b. $1^{\text {st }}$ box: 'I know that e does not hold (no-one has called for help yet).'
c. $2^{\text {nd }}$ box: 'I assume you also know that.'
d. $3^{\text {rd }}$ box: 'I don't know if you long for e (calling for help), and if you want me to intend to do it.'
e. $4^{\text {th }}$ box: 'I assume that you know if you desire and intend that I call for help.'
f. $5^{\text {th }}$ box: 'I wish to know if you desire and intend that I call for help.'
g. $6^{\text {th }}$ box: 'I want you to share this desire and intention with me.' 


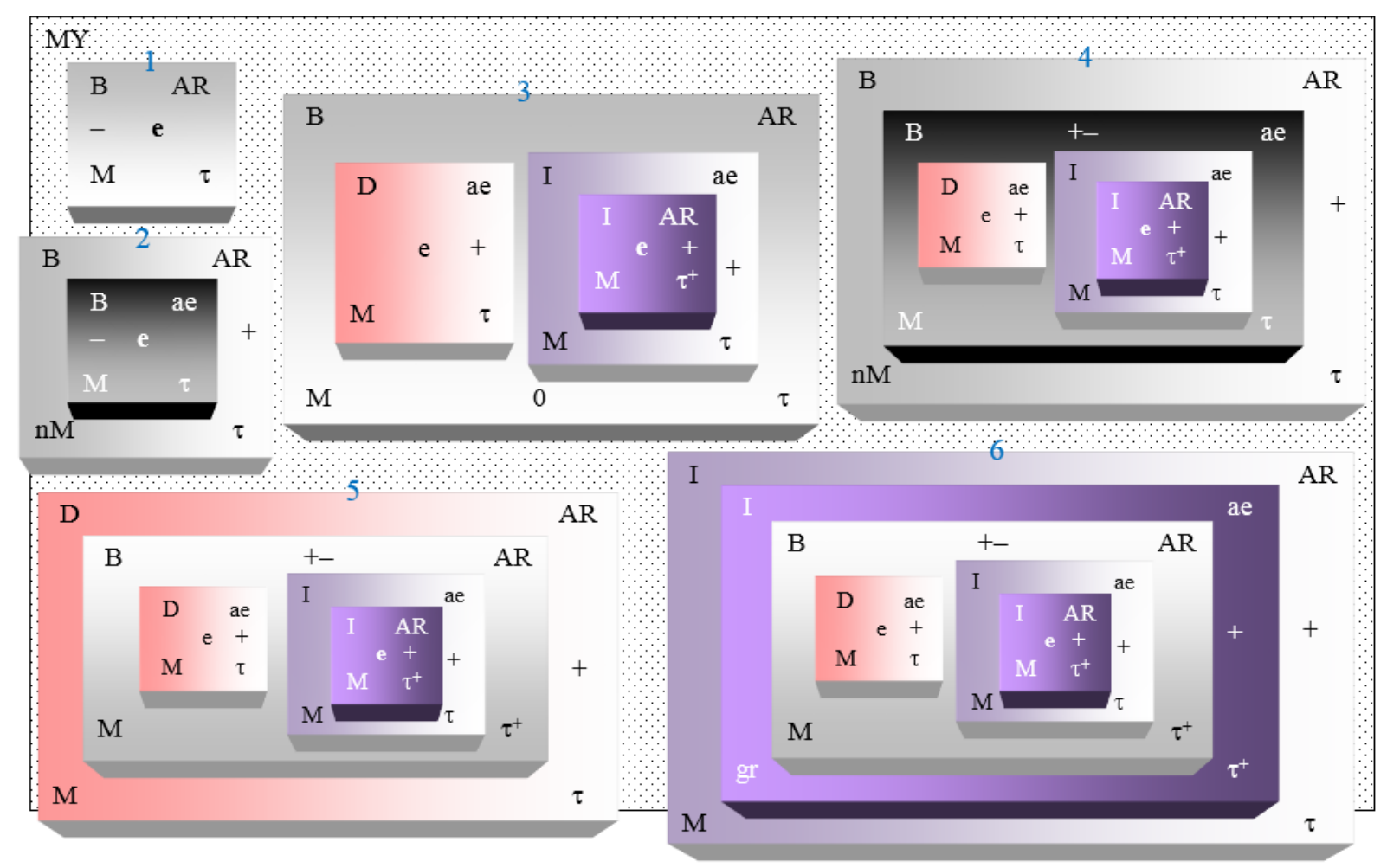

Figure 3: The intensional profile of the basic interrogative imperative sentence type in Hungarian

Thus, we have generated the required output: a question which is targeted at ae's desires and intentions in connection with a given eventuality and AR, that is, whether AR should do something or not - as long as ae is concerned.

\section{Formal Analysis: the Three Additional Types}

In this section, we briefly discuss, first, the components, and then the compositions for the other three types of interrogative imperative introduced in the paper.

\section{Pragmatico-Semantic Content of the Components}

The addition of the discourse marker ugye to a Hungarian polar question signals that AR has a preconception that eventuality e is true (leading, or biased question) (10a). The particle ugye can occur in any position in the sentence (Kenesei, Vágó, \& Fenyvesi, 1998) with a slightly different meaning (Molnár, 2016). The intensional profile of ugye-interrogatives differs from the basic type in only one worldlet which encodes that AR has a non-maximal belief that eventuality e holds, that is, there is a bias towards the positive answer (Table 2, second column, bold fonts). 
(10) Three additional types of interrogative in Hungarian

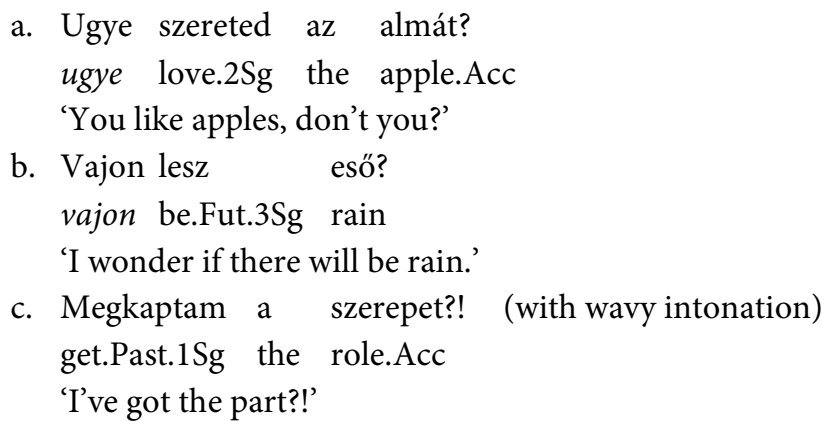

The addition of the discourse marker vajon (10b) makes a question "reflective" (Gärtner \& Gyuris, 2012), which means that, instead of asking someone a question, we merely pose the question. It "puts the question on the table" without requesting an answer (pp. 416). In the formalism of ReALIS, this attitude is expressed by the bold parts of Table 2, third column: 'I do not think (0) that you know the answer; and my intention with this utterance is merely that you recognize my desire to find it out.' Note that the person preferences are different for this type: ae is also dispreferred, since AR usually wonders about a third party's actions.

Finally, the wavy-interrogative (10c) is actually more of an exclamation (Varga, 1994), and thus, it has a very different intensional profile (Table 2, last column, bold fonts): 'I have just found out that e is true; I have had strong (positive or negative) desire for e; and I would like to get some kind of explanation (B') for this unexpected happening.' In this case, there are no verb form preferences, since AR can be surprised upon any fact.

Table 2: Intensional profiles of the components (bold: differences from the basic type)

\begin{tabular}{|c|c|c|c|c|}
\hline & Basic interrogative & Ugye-interrog. & Vajon-interrog. & Wavy-interrog. \\
\hline \multirow{3}{*}{ 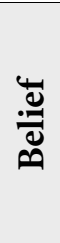 } & \multirow{2}{*}{$\langle\mathrm{B}, \mathrm{M}, \mathrm{AR}, \tau, 0\rangle$} & $\langle\mathrm{B}, \mathrm{M}, \mathrm{AR}, \tau, 0\rangle$ & \multirow{2}{*}{$\langle\mathrm{B}, \mathrm{M}, \mathrm{AR}, \tau, 0\rangle$} & $\langle\mathrm{B}, \mathrm{M}, \mathrm{AR}, \tau,+\rangle$ \\
\hline & & $\langle\mathbf{B}, \mathbf{n M}, \mathrm{AR}, \tau,+\rangle$ & & $\left\langle\mathrm{B}, \mathrm{M}, \mathrm{AR}, \tau^{-}, 0\right\rangle$ \\
\hline & $\begin{array}{c}\langle\mathrm{B}, \mathrm{nM}, \mathrm{AR}, \tau,+\rangle \\
\langle\mathrm{B}, \mathrm{M}, \mathrm{ae}, \tau,+-\rangle\end{array}$ & $\begin{array}{c}\langle\mathrm{B}, \mathrm{nM}, \mathrm{AR}, \tau,+\rangle \\
\langle\mathrm{B}, \mathrm{M}, \mathrm{ae}, \tau,+-\rangle\end{array}$ & $\begin{array}{c}\langle\mathrm{B}, \mathrm{nM}, \mathrm{AR}, \tau,+\rangle \\
\langle\mathrm{B}, \mathrm{M}, \mathrm{ae}, \tau, \mathbf{0}\rangle\end{array}$ & \\
\hline \multirow{2}{*}{ : } & \multirow{2}{*}{$\begin{array}{c}\langle\mathrm{D}, \mathrm{M}, \mathrm{AR}, \tau,+\rangle \\
\left\langle\mathrm{B}, \mathrm{M}, \mathrm{AR}, \tau^{+},+-\right\rangle\end{array}$} & \multirow{2}{*}{$\begin{array}{c}\langle\mathrm{D}, \mathrm{M}, \mathrm{AR}, \tau,+\rangle \\
\left\langle\mathrm{B}, \mathrm{M}, \mathrm{AR}, \tau^{+},+-\right\rangle\end{array}$} & \multirow{2}{*}{$\begin{array}{c}\langle\mathrm{D}, \mathrm{M}, \mathrm{AR}, \tau,+\rangle \\
\left\langle\mathrm{B}, \mathrm{M}, \mathrm{AR}, \tau^{+},+-\right\rangle\end{array}$} & $\langle\mathrm{D}, \mathrm{M}, \mathrm{AR}, \tau,+-\rangle$ \\
\hline & & & & $\begin{array}{c}\langle\mathrm{D}, \mathrm{nM}, \mathrm{AR}, \tau,+\rangle \\
\langle\mathrm{B}, \mathrm{M}, \mathrm{AR}, \tau,+\rangle\end{array}$ \\
\hline : & $\begin{array}{c}\langle\mathrm{I}, \mathrm{M}, \mathrm{AR}, \tau,+\rangle \\
\langle\mathrm{I}, \mathrm{gr}, \mathrm{ae}, \tau,+\rangle \\
\left\langle\mathrm{B}, \mathrm{M}, \mathrm{AR}, \tau^{+},+-\right\rangle\end{array}$ & $\begin{array}{c}\langle\mathrm{I}, \mathrm{M}, \mathrm{AR}, \tau,+\rangle \\
\langle\mathrm{I}, \mathrm{gr}, \mathrm{ae}, \tau,+\rangle \\
\left\langle\mathrm{B}, \mathrm{M}, \mathrm{AR}, \tau^{+},+-\right\rangle\end{array}$ & $\begin{array}{c}\langle\mathrm{I}, \mathrm{M}, \mathrm{AR}, \tau,+\rangle \\
\langle\mathrm{B}, \mathbf{M}, \mathbf{a e}, \tau,+\rangle \\
\langle\mathrm{D}, \mathbf{M}, \mathrm{AR}, \tau,+\rangle \\
\left\langle\mathbf{B}, \mathbf{M}, \mathrm{AR}, \tau^{+},+-\right\rangle\end{array}$ & \\
\hline Zँ & $\begin{array}{c}\text { Pref.: } A g=a e ; \\
\text { Dispref.: } A g \neq A R\end{array}$ & $\begin{array}{c}\text { Pref.: Ag=ae; } \\
\text { Dispref.: } A g \neq A R\end{array}$ & 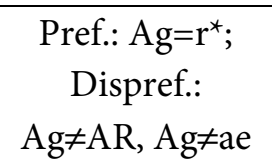 & \\
\hline
\end{tabular}

We have demonstrated in the Data section that there is a subtle difference in the acceptability of the dispreferred second-person verb form. The Note row provides an explanation for this observation. Primarily, the imperative profile's preference gets reversed; 
however, when the imperative profile is combined with an interrogative profile, its preference can slightly alter that. The first two types (basic and ugye) have the same preferences as the imperative profile, which results that the dispreference will be strong against the second-person form for these combinations. On the other hand, the last two types (vajon and wavy) have different preference or no preference at all (the original preference is not supported), and thus, the dispreference will be weaker in these cases.

\section{The Compositions}

We can use the same compositional mechanism to construct the intensional profiles for the other three types. We take the premise components of the imperative profile, and unite them with the concatenation of the relevant interrogative profile and the central components of the imperative profile (11).

(11) Construction of the intensional profiles for the further types of interrogative imperative
a. ugye (bias) + subjunctive (US) US $=$ P_Imp $\cup\left(\operatorname{Int}_{\text {ugye }} \wedge\right.$ C_Imp)
b. $\operatorname{vajon}($ self-reflection $)+$ subj. (VS) $\mathrm{VS}=\mathrm{P} \_\mathrm{Imp} \cup\left(\mathrm{Int}_{\mathrm{vajon}}{ }^{\wedge} \mathrm{C} \_\mathrm{Imp}\right)$

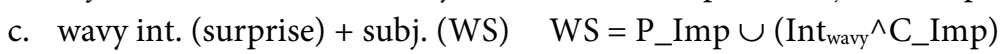

These operations create embeddings similar to those we have seen with the first type, resulting in the following output: the interrogation / bias / speculation / surprise pertains not to eventuality e but to the "commanding" of e - which is exactly the pragmatico-semantic content we can assign to these utterances.

\section{A Note on Differences in Word Order}

Let us return to the observation presented in the (b)-examples in (1-4) that interrogative imperatives can often appear with two word-order variants: the verb stem can be both followed and preceded by the verbal modifier. The pair of examples in (12a,b), a variant of ( $1 a-b)$, evokes the problem.

(12) Subjunctive + rise-fall intonation (typically used with polar questions)
a. [Hívjunk segítséget] / [??Segítséget hívjunk] a sérülthöz?
call.Sbjv.1Pl help.Acc help.Acc call.Sbjv.1Pl the wounded.All
'Should we call for help to the wounded?'
a'. Mindenekelőtt ?[hívtunk segítséget] / ${ }^{\vee}$ [segítséget hívtunk] a sérülthöz. first_of_all call.Past.1Pl help.Acc help.Acc call.Past.1Pl the wounded.All 'First of all, we called for help to the wounded.'
b. Fel-hívjam / Hívjam fel Marit? vm-call.Sbjv.1Sg call.Sbjv.1Sg vm Mari.Acc (vm: verbal modifier) 'Should I call Mari?'

As shown by (12a'), the object readily serves as a verbal modifier in the given construction (i.e., the equivalent of call for help); however, the corresponding interrogative imperative strongly prefers the order with the verb stem preceding the verbal modifier (12a). Note that, in 
the case of embedded imperatives, this order is (generally) claimed to express a stronger deontic force by Tóth (2005), relative to the other word order, expressing a weak(er) deontic force. As for (12b), the verbal construction presented there contains a preverb serving as a verbal modifier. The preverb proves to tolerate both word-order variants. One question is as to whether there is really a difference in the strength of deontic force between the word-order variants in (12b). Another question is as to whether non-preverb-like verbal modifiers prefers one word-order variant.

The latter question is left to future research. As for the former question, our mother-tongue competence says that the variant which stronger deontic force is attributed to is really a request for a more resolute, more disciplined instruction. Nevertheless, it seems to be impossible to construct world models safely differentiating the word-order variants in question. Nor is it clear how to support this differentiation by means of corpus data. What we can safely claim at this point of research is that the more sophisticated version of ReALIS which will be sketched in Table 4 in the section of conclusions and loose ends is suitable for capturing the alleged difference (by appropriately "setting" the corresponding intensitivity values belonging to intention/desire). The precise details are also left to future research.

\section{Conclusions and Loose Ends}

We have discussed four types of interrogative imperative in Hungarian, their forms and functions. Our hypothesis was that the pragmatico-semantic content of mixed-type sentences can be obtained compositionally. For the analysis, we applied the formal dynamic discourseand mind-representation theory ReALIS.

We combined the intensional profiles of the components by using the simple operation of concatenation, on the one hand, and a formalized version of pragmasemantic blending, on the other hand. With this method, we have constructed the intensional profiles for these mixedtype sentences compositionally: the interlocutors' beliefs, desires and intentions behind the four types of interrogative imperative.

The analysis has produced the required output. For each type of interrogative imperative, it has derived the exact meaning we aimed for, namely that the interrogation / bias / speculation / surprise pertains not to eventuality e but to the "commanding" of e. The analysis has also provided an explanation for the subtle difference in the acceptability of certain forms.

In these cases, the data confirmed our hypothesis: the pragmatico-semantic content of the interrogative imperative profile can be constructed compositionally from the intensional profiles of its components. In the future, we plan to expand the scope of this research and see whether we can account for more linguistic phenomena via this pragmatic compositional mechanisms.

We conclude the paper by presenting a summarizing table (Table 3) about the features we have discussed on the topic of interrogative imperatives in Hungarian, and another table (Table 4) with a more sophisticated intensional-profile model of the three basic sentence types (Szeteli \& Alberti, 2017), upon which the description of mixed-type sentences are also hypothesized to be based compositionally. 
Table 3: Summary of the Hungarian interrogative imperative sentence types discussed in the paper

\begin{tabular}{|c|c|c|c|c|}
\hline & BS (1) & US (2) & VS (3) & WS (4) \\
\hline $\begin{array}{c}\text { Form: } \\
\text { Subjunctive+ }\end{array}$ & $\begin{array}{c}\text { rise-fall } \\
\text { intonation }\end{array}$ & $\begin{array}{l}\text { particle } \\
\text { ugye }\end{array}$ & $\begin{array}{l}\text { particle } \\
\text { vajon }\end{array}$ & $\begin{array}{c}\text { wavy } \\
\text { intonation }\end{array}$ \\
\hline $\begin{array}{c}\text { Person } \\
\text { preferences }\end{array}$ & 1. (??2.) & 1. $(? 2)$. & 1. $(2)$. & 1. ( $(2)$. \\
\hline $\begin{array}{c}\text { vm-verb stem } \\
\text { order }\end{array}$ & nuclear (inverted) & $\begin{array}{c}\text { nuclear } \\
\text { (inverted) }\end{array}$ & nuclear ('inverted) & $\begin{array}{c}\text { inverted } \\
\text { ('nuclear) } \\
\end{array}$ \\
\hline Function & $\begin{array}{l}\text { requesting } \\
\text { instruction }\end{array}$ & $\begin{array}{c}\text { requesting } \\
\text { instruction } \\
\text { (confirmation) }\end{array}$ & $\begin{array}{l}\text { requesting } \\
\text { opinion } \\
\text { (speculate } \\
\text { together) }\end{array}$ & $\begin{array}{l}\text { expressing surprise } \\
\text { over instruction } \\
\text { (requesting confirmation } \\
\text { /explanation/sympathy...) }\end{array}$ \\
\hline Answer & $\begin{array}{c}\text { yes / no } \\
\text { (subjunct.) }\end{array}$ & $\begin{array}{c}\text { yes / no } \\
\text { (+explanation) }\end{array}$ & $\begin{array}{c}\text { I think... / } \\
\text { Maybe... / ... }\end{array}$ & $\begin{array}{c}\text { Yes / Yes, because... / I am } \\
\text { sorry! / ... }\end{array}$ \\
\hline Components & $\begin{array}{l}\text { basic question }+ \\
\text { basic imperative }\end{array}$ & $\begin{array}{l}\text { biased question }+ \\
\text { basic imperative }\end{array}$ & $\begin{array}{c}\text { self-reflective } \\
\text { question + basic } \\
\text { imperative }\end{array}$ & $\begin{array}{c}\text { exclamative question }+ \text { basic } \\
\text { imperative }\end{array}$ \\
\hline $\begin{array}{l}\text { Constructing } \\
\text { formula }\end{array}$ & $\begin{array}{c}\text { P_Imp } \cup \\
\left(\text { Int }_{\text {basic }} \wedge \text { C_Imp }\right.\end{array}$ & $\begin{array}{c}\text { P_Imp } \cup \\
\left(\text { Int }_{\text {ugye }} \wedge \text { C_Imp }\right)\end{array}$ & $\begin{array}{c}\text { P_Imp } \cup \\
\left(\operatorname{Int}_{\text {vajon }} \wedge \text { C_Imp }\right)\end{array}$ & $\begin{array}{c}\text { P_Imp } \cup \\
\left(\text { Int }_{\text {wavy }} \wedge \text { C_Imp }\right)\end{array}$ \\
\hline \multirow{2}{*}{ Meaning } & the question & the bias & the speculation & the surprise \\
\hline & \multicolumn{4}{|c|}{ pertains to the "commanding" of e: ae's desires and intentions concerning e } \\
\hline
\end{tabular}

The point of departure is still that $\mathrm{AR}$ is convinced that the distribution of knowledge concerning a potential fact $\mathrm{e}$ is as follows: AR knows it while ae does not know it in the case of a declarative, and, in the case of an interrogative sentence, exactly oppositely, while in the case of an imperative, both interlocutors are assumed to know that the world is such that e does not hold. 
Table 4: A generalized model of the intensional profiles of the three basic sentence types in Hungarian (bold: essential differences from the earlier $\mathfrak{P}$ ieALIS-model partly demonstrated in Table 2)

\begin{tabular}{|c|c|c|c|c|}
\hline & $\begin{array}{c}\text { Conditions on } \\
\text { parameter values }\end{array}$ & Declarative & Interrogative & Imperative \\
\hline \multirow{2}{*}{ 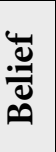 } & & $\langle\mathrm{B}, \mathrm{M}, \mathrm{AR}, \tau,+\rangle$ & $\langle\mathrm{B}, \mathrm{M}, \mathrm{AR}, \tau, 0\rangle$ & $\langle\mathrm{B}, \mathrm{M}, \mathrm{AR}, \tau,-\rangle$ \\
\hline & $\lambda=\langle\mathrm{B}, \mathrm{nM}, \mathrm{AR}, \tau,+\rangle$ & $\lambda \wedge\langle\mathrm{B}, \mathrm{M}, \mathrm{ae}, \tau, 0\rangle$ & $\lambda \wedge\langle\mathrm{B}, \mathrm{M}, \mathrm{ae}, \tau,+-\rangle$ & $\lambda \wedge\langle\mathrm{B}, \mathrm{M}, \mathrm{ae}, \tau,-\rangle$ \\
\hline • & $\begin{array}{c}\lambda^{\prime}=\langle\mathrm{B}, \mathrm{nM}, \mathrm{AR}, \boldsymbol{\tau},+\rangle ; \\
\lambda^{\prime \prime}=\left\langle\mathrm{D}, \boldsymbol{\gamma}_{\left.\mathbf{r}^{*}, \mathbf{r}^{*}, \boldsymbol{\tau},+\right\rangle}\right. \\
\Sigma \gamma_{\mathrm{x}} \geq \mathbf{l}\left(\mathbf{x} \in \mathbf{r}^{\star}\right)\end{array}$ & $\lambda^{\prime} \wedge \lambda^{\prime \prime} \wedge\left\langle\mathrm{B}, \mathrm{M}, \mathrm{ae}, \tau^{+},+-\right\rangle$ & $\lambda^{\prime} \wedge \lambda^{\prime \prime} \wedge\left\langle\mathrm{B}, \mathrm{M}, \mathrm{AR}, \tau^{+},+-\right\rangle$ & $\lambda "$ \\
\hline : & $\begin{array}{c}\lambda^{\prime \prime \prime}=\langle\mathrm{I}, \mathrm{M}, \mathrm{AR}, \tau,+\rangle ; \\
\lambda^{\prime \prime \prime \prime}=\left\langle\mathrm{I}, \mathrm{M}, \mathrm{ae}, \tau^{+},+\right\rangle\end{array}$ & $\lambda^{\prime \prime \prime} \wedge\left\langle\mathrm{B}, \mathrm{M}, \mathrm{ae}, \tau^{+},+\right\rangle$ & $\lambda^{\prime \prime \prime} \wedge \lambda^{\prime \prime \prime \prime} \wedge\left\langle\mathrm{B}, \mathrm{M}, \mathrm{AR}, \tau^{+},+-\right\rangle$ & $\lambda " ' \wedge \lambda " '$ \\
\hline$\frac{0}{0}$ & Pref.: $\mathbf{r}^{\star}=\{$ AR,ae $\}$ & $\begin{array}{l}\text { Pref.: } A g=A R, \\
\text { Dispref.: Agfae }\end{array}$ & $\begin{array}{c}\text { Pref.: } A g=a e ; \\
\text { Dispref.: } A g \neq A R\end{array}$ & $\begin{array}{c}\text { Pref.: Ag=ae; } \\
\text { Dispref.: Ag } \neq A R\end{array}$ \\
\hline
\end{tabular}

It is the underlying desire that is handled in a more sophisticated way than in the earlier versions of $\Re$ eALIS. The point is that it is not $a b$ ovo decided whether AR (see $\lambda^{\prime}$ ) is led by selfinterest or cooperation while performing either a declarative (cf. Oishi, 2014), or an interrogative, or an imperative (see Kleiber et al., 2016). Referent $\mathrm{r}^{\star}$ in the relevant formula can refer to not only a singleton but, preferably, a set of people. We claim that the most preferred choice is the pair of AR and ae (that is, the two interlocutors are taken into consideration), and the formula ' $\Sigma \gamma_{\mathrm{x}} \geq 1$ ' (after having converted intensity degrees of the three modalities into numbers between 0 and 1 in the plausible way with 1 corresponding to $M(a x)$ ) can capture both (i) the case when performing the utterance serves AR's interest (who wants to involve ae in a project serving his/her own interest by "forcing" the information on ae, or asking for it, or requesting common intention, see the Intention-row), and (ii) the case when AR indends to serve ae's interest (by giving ae some information, or accepting it, or offering common intention). Let us return to the interpretation of the worldlet label $\lambda$ " with the formula of summation: the evaluation $\gamma_{\mathrm{AR}}=1$ captures self-interest, while $\gamma_{\mathrm{ae}}=1$ means inclination for cooperation. As indicated by the relation symbol ' $\geq$ ', it is not excluded at all that AR assumes that his/her self-interest fortunately coincides with ae's interest (e.g., both intensitivity value can be $0.7=$ 'fairly strong desire', resulting in a sum of 1.4). Obviously, even this formula is only the first step towards a would-be system of formulas precisely capturing the cross-checking of each interests assumed by AR while performing a given sentence type. It must be taken into account, however, that the task is not revealing every combination of interests occurring in every-day life but collecting those which can be expressed by the basic sentence types without any kind of "fine-tuning" with (collocated) discourse markers and special stress patterns.

All in all, we are ceaselessly sophisticating (i) what can plausibly be assumed to be the basic intensional-profile types, (ii) the intensional-profile descriptions of discourse markers, and (iii) 
the blending formulas "controlling" the calculation of the intensional profiles of sentences types fine-tuned by discourse-marker collocations.

\section{References}

Alberti, G. (2011). ЯieALIS: Interpretálók a világban, világok az interpretálóban [Interpreters in the world, worlds in the interpreter]. Budapest, Hungary: Akadémiai Kiadó.

Alberti, G., Dóla, M., \& and Kleiber, J. (2014). Mood and modality in Hungarian: Discourse Representation Theory meets Cognitive Linguistics. Argumentum, 10, 172-191.

Alberti, G., \& Kleiber, J. (2014). ReALIS: Discourse Representation with a Radically New Ontology. In L. Veselovská \& M. Janebová (Eds.), Complex Visibles Out There. Olomouc Modern Language Series 4 (pp. 513528). Olomouc, Czech Republic: Palacký University.

Alberti, G., Kleiber, J.; Schnell, Z.; \& Szabó, V. (2016). Intensional profiles and different kinds of human minds: "Case studies" about Hungarian imperative-like sentence types. Linguistics Beyond and Within, 2, 6-26.

Alberti, G., Vadász, N., \& Kleiber, J. (2014). Ideal and Deviant Interlocutors in a Formal Interpretation System. In A. Zuczkowski, R. Bongelli, I. Riccioni, \& C. Canestrari (Eds.), Communicating Certainty and Uncertainty in Medical, Supportive and Scientific Contexts. Dialogue Studies 25 (pp. 59-78). Amsterdam, The Netherlands: John Benjamins.

Asher, N., \& Lascarides, A. (2003). Logics of Conversation. Cambridge, UK: Cambridge University Press.

Gärtner, HM., \& Gyuris, B. (2012). Pragmatic markers in Hungarian: Some introductory remarks. Acta Linguistica Hungarica, 59, 387-426.

Gyuris, B. (2009). Sentence-types, discourse particles and intonation in Hungarian. In T. Solstad \& A. Riester (Eds.), Proceedings of Sinn und Bedeutung 13 (pp. 157-171). Stuttgart, Germany: Online Publikationsverbund der Universität Stuttgart (OPUS).

Kamp, H., van Genabith, J., \& Reyle, U. (2011). Discourse Representation Theory. In D. Gabbay, \& F. Guenthner (Eds.), Handbook of Philosophical Logic (pp. 125-394). Berlin, Germany: Springer.

Kenesei, I., Vágó, R. M., \& Fenyvesi, A. (1998). Hungarian. London, UK: Routledge.

Kleiber, J., \& Alberti, G. (2014). Uncertainty in Polar Questions and Certainty in Answers? In S. Cantarini, W. Abraham, \& E. Leiss (Eds.), Certainty-uncertainty - and the attitudinal space in between. Studies in Language Companion Series 165 (pp. 135-152). Amsterdam, The Netherlands: John Benjamins.

Kleiber, J., Alberti, G., \& Szabó, V. (2016). The intensional profiles of five Hungarian imperative sentence types. Linguistica, 56(1), 161-172.

Lauer, S. (2013). Towards a dynamic pragmatics (Unpublished doctoral dissertation). Stanford University, Stanford, CA.

Molnár, C. S. (2016). Ugye melyik szabály alól ne találnánk kivételt? Az ugye partikula előfordulása kiegészítendő kérdésekben [There is an exception to every rule, isn't there? The distribution of the Hungarian particle ugye in wh-questions]. Jelentés és Nyelvhasználat, 3, 151-167.

Oishi, E. (2014). Discursive functions of evidentials and epistemic modals. In S. Cantarini, W. Abraham, \& E. Leiss (Eds.), Certainty-uncertainty - and the attitudinal space in between. Studies in Language Companion Series 165 (pp. 239-262). Amsterdam, the Netherlands: John Benjamins.

Potts, C. (2005). The logic of conventional implicatures. New York, NY: Oxford University Press.

Szeteli, A., \& Alberti, G. (2017). Enszerintem, teszerinted 'in my/your opinion'. Poster presented at the 2017 Debrecen Workshop on Pronouns. In Gy. Rákosi (Ed.), Book of Abstracts - DWP2017 (pp. 43-44). Debrecen, Hungary: Institute for English and American Studies.

Turi, G. (2009). Kötőmód a mai magyar nyelvben [The subjunctive in present-day Hungarian]. Argumentum, 5, $25-38$.

Tóth, E. (2005). Az alárendelt mellékmondatbeli kötö-, ill. felszólitó módról [On the subjunctive vs. imperative mood in subordinate clauses]. In: B. Sinkovics (Ed.), LingDok4 (pp. 175-193). Szeged, Hungary: University of Szeged. 
Varga, D. (2013). A magyar felszólító mondatok szerkezete [The structure of Hungarian imperative sentences] (Unpublished doctoral dissertation). Pázmány Péter University, Budapest, Hungary.

Varga, L. (1994). A hanglejtés [Intonation]. In F. Kiefer (Ed.), Strukturális Magyar Nyelvtan 2. Fonológia [A Structural Grammar of Hungarian 2. Phonology] (pp. 468-549). Budapest, Hungary: Akadémiai Kiadó. 